\section{Patients' Knowledge and Awareness towards Use of Antibiotics in Bangladesh: A Cross-sectional Study Conducted in Three Tertiary Healthcare Centers in Bangladesh}

\author{
*Moni Rani Saha ${ }^{1}$, Shammy Sarwar ${ }^{1}$, Manik Chandra Shill ${ }^{2}$ and \\ Mohammad Shahriar ${ }^{3}$ \\ ${ }^{1}$ Department of Pharmacy, Stamford University Bangladesh \\ 51 Siddeswari Road, Dhaka-1217, Bangladesh. \\ ${ }^{2}$ IPD Pharmacy, Square Hospitals Ltd., West Panthapath, \\ Dhaka-1205, Bangladesh. \\ ${ }^{3}$ Department of Pharmacy, The University of Asia Pacific \\ Dhanmondi, Dhaka-1209, Bangladesh.
}

\author{
*Corresponding Author: \\ Moni Rani Saha \\ Assistant Professor \\ Department of Pharmacy \\ Stamford University Bangladesh \\ 51, Siddeswari Road \\ Dhaka-1217, Bangladesh. \\ Contact No.: +8801711013960 \\ E-mail: saha_moni1978@yahoo.com
}

Received - 02 May 2010

Accepted for Publication - 17 May 2010

\begin{abstract}
This study is aimed to estimate general knowledge and awareness of patients regarding use of antibiotics to find out possible reasons of irrational use of antibiotics in Bangladesh. It was a questionnaire based crosssectional health survey conducted on 350 subjects aged 18 or over who came to get service at three tertiary healthcare centers named Dhaka Medical College (DMC) Hospital, Sir Salimullah Medical College (SSMC) Mitford Hospital and Bangabandhu Sheikh Mujib Medical University (BSMMU) Hospital of Dhaka, Bangladesh. It was found from the study that the general knowledge of the patients about the indication of antibiotics was very poor. Majority of the patients did not know the appropriate use of antibiotics. Only $26 \%$ respondents answered correctly that antibiotics are indicated for bacterial infections. In addition, 38.97\% of them also did not know that an antibiotic is a prescription drug and should not be used without doctor's prescription. The awareness about the patients towards use of antibiotics was also poor. A very high percentage of the patients $(51.71 \%)$ answered that they do not complete the full course of therapy. Surprisingly, $39.14 \%$ of the patients replied that they stop antibiotics when the symptoms disappear and remarkably $14.29 \%$ just make the dose double if they forget to take due dose. On the other hand, $28.86 \%$ of the patients said that they do not maintain dosing schedule during the course of therapy. Moreover, prevalence of self-medication with antibiotics in cold and fever was also extremely high $(60.86 \%)$. This study indicates that there is an urgent need of health education for the community to increase knowledge and awareness about use of antibiotics to decrease the self-medication and inappropriate use of antibiotics.
\end{abstract}

Key words: Antibiotics, General Knowledge, Awareness, Tertiary Healthcare Center, Health Education

\title{
INTRODUCTION
}

Antibiotics are extremely important medicine in the treatment of infectious diseases, but unfortunately bacteria are capable of developing resistance to them. Self-medication of antimicrobial drugs is one of the main causes of antimicrobial resistance and should be taken into account as a major concern because it may spread antimicrobial drug resistance which is a major public health problem worldwide (Harbarth and Samore, 2005; Malhotra et al.,2007). Antimicrobial resistance is a rapidly increasing problem in the management of infectious diseases that needs urgent action. Bacterial resistance to one or more front-line antimicrobials pose numerous challenges to healthcare that may result in patient morbidity and mortality with increased drug costs, prolonged duration of illness, and more expensive disease control measures (Harbarth and Samore, 2005; Levy, 2005). Bangladesh has made substantial progress in drug manufacturing since the introduction of its National Drug Policy (NDP) in 1982, but irrational use, inappropriate prescribing and unjustified self medication of drugs especially antibiotics are suspected as common problems that affecting the total healthcare system seriously. In Bangladesh antibiotics can be obtained from pharmacies and drug stores without the requirement of a prescription. As a result, many ailments like viral flu or fever are often self- treated with antimicrobials. 
A number of studies indicate the lack of public knowledge and awareness about antibiotics is one of the causes behind antibiotic resistance (Branthwaite et al. 1996; Arroll et al. 1999; Malhotra et al., 2007). The purpose of this study is aimed to estimate the general knowledge and awareness of the people towards use of antibiotics in order to predict reasons behind irrational use of antibiotics in Bangladesh.

\section{MATERIALS AND METHODS}

A cross-sectional health survey was conducted with a standardized questionnaire by interviewing 350 subjects who came to get service at outpatient departments of Dhaka Medical College (DMC) Hospital, Sir Salimullah Medical College (SSMC) Mitford Hospital and Bangabandhu Sheikh Mujib Medical University (BSMMU) Hospital under Dhaka district in Bangladesh. These tertiary healthcare centers were selected as survey places because these hospitals are the most important among the tertiary hospitals in Bangladesh where a large number of patients come every day for the treatment of various diseases. The duration of study was 2 months starting from March 2010 to April 2010. The questionnaire of the study was comprised of questions indicating information on general knowledge, awareness, record of buying antibiotics without prescription, record of selfmedication without prescription along with demographic characteristics. The data were collected from the patients who were 18 years or more and had heard about antibiotic and used at least one antibiotic without prescription within the last 12 months. Few questionnaires were excluded during data analysis because of inadequate information. The survey questionnaires were pilot-tested prior to the main survey. The data was subjected to simple descriptive statistical analyses including frequency distribution, mean and finally was expressed in percentage.

\section{RESULTS AND DISCUSSION}

Table 1 provides information on socio-demographic characteristics of the patients and Figure 1 shows the reasons of patients' visit to hospitals.

Table 1: Socio-demographic characteristics of the patients.

\begin{tabular}{llll}
\hline Socio-demographic & Characteristics & Frequency (N=350) & Percentage (\%) \\
\hline Sex & Male & 240 & 68.57 \\
& Female & 110 & 31.43 \\
\hline Age in Years & $18-30$ & 151 & 43.14 \\
& $31-40$ & 80 & 22.86 \\
& $41-50$ & 66 & 18.86 \\
& $51-60$ & 39 & 11.14 \\
& $\geq 60$ & 14 & 4.00 \\
\hline Education & No education & 96 & 27.43 \\
& Below SSC & 145 & 41.43 \\
& SSC-HSC & 77 & 22.00 \\
& Graduate or above & 32 & 9.14 \\
\hline Occupation & Business & 84 & 24.00 \\
& Service & 65 & 18.57 \\
& House Wife & 60 & 17.14 \\
& Student & 46 & 13.14 \\
& Others & 95 & 27.14 \\
\hline
\end{tabular}


Saha et al., 2010

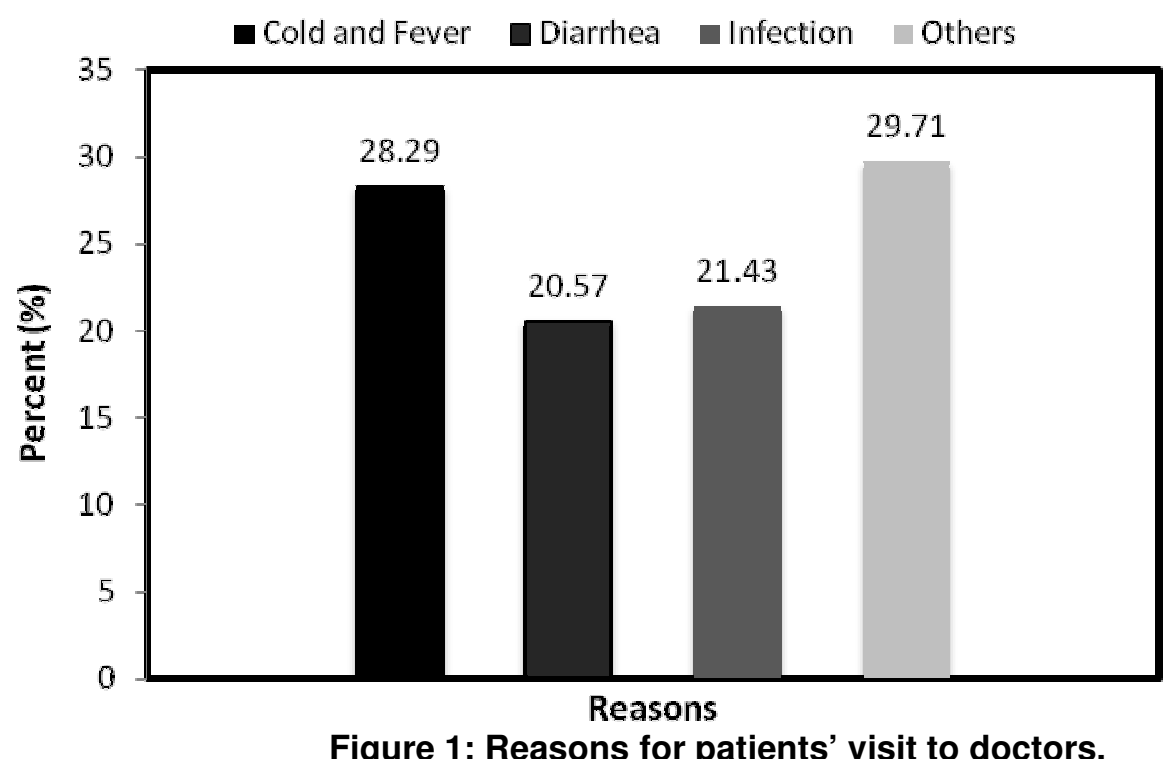

The socio-demographic characteristics of the persons reveal that majority of them (68.57\%) were male. $43.14 \%$ of the patients were under the age of $18-30$ years. Education level of $41.43 \%$ of the patients was below SSC. However, most of the subjects were engaged in business (24\%) and service (18.57\%). On the other hand, a high percentage of patients $(28.29 \%)$ came to the hospitals with cold and fever.

The table 2 shows that the general knowledge of the patients regarding the appropriate use of antibiotics was very poor. $32.57 \%$ respondents wrongly believe that antibiotics are indicated for cold and fever. Surprisingly, 30\% of them think that antibiotics can be used in any diseases while $11.43 \%$ answered incorrectly that antibiotics are used for pain. Only $26 \%$ of the patients gave the correct answer about the indication of antibiotics. In addition, $38.97 \%$ of them did not know that antibiotic is a prescription drug and should not be used without prescription. These results indicate that majority of the respondents have misconceptions about the appropriate use of antibiotics and a high percentage of respondents do not know that antibiotics are prescription drugs. Several studies also have shown that patients often do not have accurate knowledge of antibiotics (Chretien et al., 1975; Hong et al. 1999). Hong et al., for example, found that patients often could not identify whether a medication was an antibiotic or not and that many patients considered antibiotics to be any prescription medication (Hong et al. 1999).

Table 2: Patients' general knowledge about antibiotics.

\begin{tabular}{llll}
\hline Question Pattern & Response Pattern & $\begin{array}{l}\text { Frequency } \\
\text { N=350 }\end{array}$ & Percent \\
\hline Indication of antibiotics & Bacterial infection & 91 & 26.00 \\
& Cold and fever & 114 & 32.57 \\
& Pain & 40 & 11.43 \\
& Any disease & 105 & 30.00 \\
\hline Antibiotic is a prescription & Yes & 214 & 61.03 \\
drug & No & 136 & 38.97 \\
\hline
\end{tabular}

On the other hand, the awareness of the patients towards use of antibiotics was also poor. Table 3 depicts that only $48.29 \%$ of the patients mentioned that they always complete the full course of therapy whereas $51.71 \%$ do not complete full course. While $52.57 \%$ of the subjects stated that they always maintain dosing schedule during the course of therapy. A high percentage of respondents $(39.14 \%)$ stated that they stop taking antibiotics when the symptoms disappear and a remarkable percentage of patients (14.29\%) just make the dose double if they forget to take the due dose in time. 
Prevalence of self-medication with antibiotics in cold and fever was also very high (60.86\%). A fairly high percentage $(58.57 \%)$ of patients admits that they purchase antibiotics without prescription from the pharmacy. Majority of the subjects $(61.14 \%)$ also answered that they store antibiotics for future use. On the other hand, $35.14 \%$ of the respondents agreed that they use same antibiotic for different diseases.

Table 3: Patients' awareness about the use of antibiotics.

\begin{tabular}{llll}
\hline Question Pattern & Response Pattern & $\begin{array}{c}\text { Frequency } \\
\mathbf{N = 3 5 0}\end{array}$ & $\begin{array}{c}\text { Percent } \\
\text { (\%) }\end{array}$ \\
\hline Record of completion of full antibiotic & Yes & 169 & 48.29 \\
course & No & 181 & 51.71 \\
\hline Time of stop taking of antibiotics & After completion of course & 213 & 60.86 \\
& When symptoms disappear & 137 & 39.14 \\
\hline Steps taken after missing of a dose & Doubling of dose & 50 & 14.29 \\
& Taking from next day and & & 36.00 \\
& others & 126 & 49.71 \\
\hline Maintenance of dosing schedule & Taking next dose & 174 & 52.57 \\
according to doctor' advice & Always & 184 & 28.86 \\
& No & 101 & 18.56 \\
\hline History of self-medication of & Sometimes & 65 & 60.86 \\
antibiotics in cold and fever & Yes & 213 & 39.14 \\
\hline History of storing antibiotics at home & No & 127 & 61.14 \\
for future use & No & 214 & 38.86 \\
\hline History of using same medicine for & Yes & 136 & 35.14 \\
different diseases & No & 123 & 64.86 \\
\hline Record of buying antibiotics without & Yes & 227 & 58.57 \\
prescription from the pharmacies & No & 205 & 41.43 \\
\hline
\end{tabular}

This study indicates lack of patients' compliance which is a key component in preventing the rise in antibiotic resistance. Our study reveals that a high percentage of the studied subjects do not complete full antibiotic course and discontinue antibiotics when symptoms disappear. A large percentage of the respondents also said that they do not maintain dosing schedule. This study also reveals that majority of the respondents had a record of self-medication in cold and fever. They also had record of storing of antibiotics at home and buying antibiotics without prescription from the pharmacies. Literature review reveals that self-medication is one of the causes of antimicrobial overuse or misuse, especially, in low- and middle-income countries, where antibiotics are easily obtained without prescription from the pharmacies (Al-Bakri et al. 2005; Berzanskyte et al. 2006).

Moreover, use of antimicrobial drugs without prescription is also often inappropriate because of using insufficient dosages or incorrect or unnecessary drugs which increases the risk of antimicrobial drug resistance and associated treatment failure and spread of resistant bacteria (Guillemot, 1998). Widespread self-treatment often with the least effective agent in an incorrect dosage is considered a major factor in the development of bacterial resistance in developing countries (Bently, 1993). Overall, this study indicates that the general knowledge and awareness of Bangladeshi people participated in this study were not sufficient. Finally, the findings of this study show that self-medication, availability of antibiotics without prescription from the pharmacies, patients' non compliance and patients' lack of knowledge and consciousness towards use of antibiotics are the main causes of irrational use of antibiotics in Bangladesh which in turn causing antimicrobial resistance that is alarming. 


\section{CONCLUSION}

Rules and regulations in Bangladesh must be strengthen and executed to decrease the sale of antibiotics without prescription which is one of the most important causes of self-medication and irrational use of antibiotics. In addition, health education is required for the community to increase public knowledge and awareness about use of antibiotics which will gradually increase patients' compliance and reduce the inappropriate use of antibiotics.

\section{REFERENCES}

Al-Bakri AG, Bustanji Y, Yousef AM. (2005) Community consumption of antibacterial drugs within the Jordanian population: sources, patterns and appropriateness. Int $J$ Antimicrob Agents, 26:389-395.

Arroll B, Everts N. (1999) The common cold: what does the public think and want? N Z Fam Physician, 26:51-56.

Benetley A. (1993) The antibiotic crisis. In problem drugs. Amsterdam Health Action International, 51-68.

Berzanskyte A, Valinteliene R, Haaijer-Ruskamp FM, Gurevicius R, Grigoryan L (2006) Selfmedication with antibiotics in Lithuania. Int J Occup Med Environ Health; 19:246-253.

Branthwaite A, Pechere JC. (1996) Pan-European survey of patients' attitudes to antibiotics and antibiotic use. J Int Med Res. 24(3):229-238.

Chretien JH, McGarvey M, deStwolinski A, Esswein JG. (1975) Abuse of antibiotics. A study of patients attending a university clinic. Arch Intern Med, 135:1063-5.

Guillemot D, Carbon C, Balkan B, Geslin P, Lecoeur H, Vauzelle-Kervroedan F, et al. (1998) Low dosage and long treatment duration of betalactam: risk factors for carriage of penicillinresistant Streptococcus pneumoniae. JAMA, 279:365-70.

Harbarth S, Samore MH. (2005) Antimicrobial resistance determinants and future control. Emerg Infect Dis; $11: 794-801$.

Hong JS, Philbrick JT, Schorling JB.(1999) Treatment of upper respiratory infections: do patients really want antibiotics? Am J Med, 107:511-5.

Levy SB (2005) Antibiotic resistance-the problem intensifies. Adv Drug Deliv Rev.; 57:1446-50.

Malhotra Kumar S, Lammens C, Coenen S, Van Herck K, Goossens H. (2007) Impactof azithromycin and clarithromycin therapy on pharyngeal carriage of macrolide-resistant streptococci among healthy volunteers: a randomised, double-blind, placebo-controlled study. Lancet 2007, 369:482-490. 